\title{
Brittle Damage Models in DYNA2D
}

\author{
D. R. Faux
}

September 1, 1997

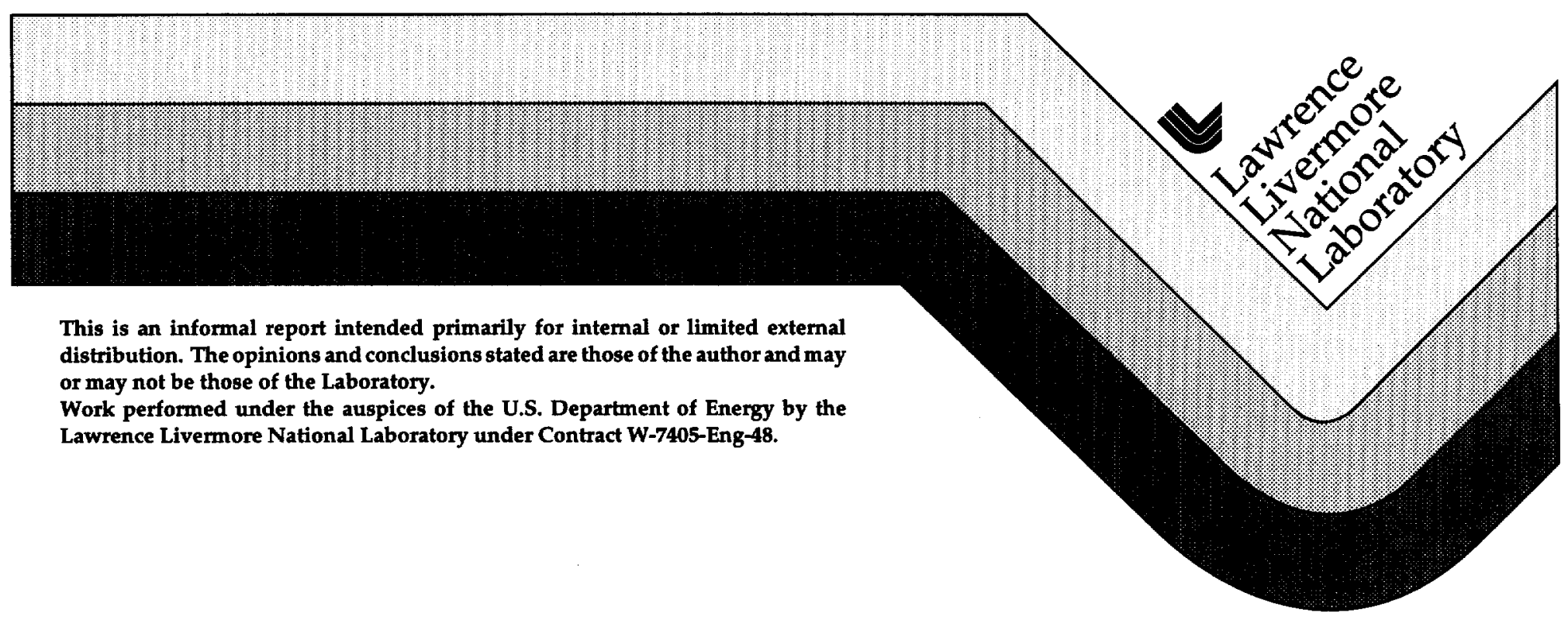




\section{DISCLAIMER}

This document was prepared as an account of work sponsored by an agency of the United States Government. Neither the United States Government nor the University of California nor any of their employees, makes any warranty, express or implied, or assumes any legal liability or responsibility for the accuracy, completeness, or usefulness of any information, apparatus, product, or process disclosed, or represents that its use would not infringe privately owned rights. Reference herein to any specific commercial product, process, or service by trade name, trademark, manufacturer, or otherwise, does not necessarily constitute or imply its endorsement, recommendation, or favoring by the United States Government or the University of California. The views and opinions of authors expressed herein do not necessarily state or reflect those of the United States Government or the University of California, and shall not be used for advertising or product endorsement purposes.

This report has been reproduced directly from the best available copy.

Available to DOE and DOE contractors from the Office of Scientific and Technical Information

P.O. Box 62, Oak Ridge, TN 37831

Prices available from (615) 576-8401, FTS 626-8401

Available to the public from the

National Technical Information Service

U.S. Department of Commerce

5285 Port Royal Rd.,

Springfield, VA 22161 


\title{
Brittle Damage Models in DYNA2D
}

\author{
Douglas R. Faux
}

September 1997

\begin{abstract}
DYNA2D ${ }^{1}$ is an explicit Lagrangianfinite element code used to model dynamic events where stress wave interactions influence the overall response of the system. DYNA2D is often used to model penetration problems involving ductile-to-ductile impacts; however, with the advent of the use of ceramics in the armor-anti-armor community and the need to model damage to laser optics components, good brittle damage models are now needed in DYNA2D. This report will detail the implementation of four brittle damage models in DYNA2D, three scalar damage models and one tensor damage model. These new brittle damage models are then used to predict experimental results from three distinctly different glass damage problems.
\end{abstract}




\section{Table of Contents}

page

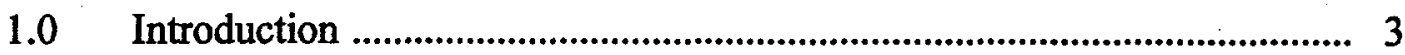

2.0 Scalar Brittle Damage Models ....................................................... 3

2.1 Modified Tuler-Butcher Brittle Damage Model....................................... 5

2.2 Modified Cagnoux-Glenn Brittle Damage Model.................................. 5

2.3 Modified Steinberg-Tipton Brittle Damage Model................................ 6

3.0 Tensor Damage Model - Modified Rubin/Attia 3D Crack Model ............. 6

4.0 Determination of the Material and Damage Parameters........................... 8

4.1 Rigid Body Penetration Through Float Glass...................................... 10

4.2 Tungsten Rod Penetration in Pyrex/4340 Steel..................................... 11

4.3 Steel Sphere Impacts Onto Fused Silica Glass...................................... 13

5.0 Comments Concerning the Use of the Various Damage Models ............... 14

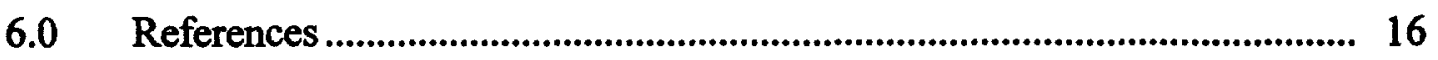

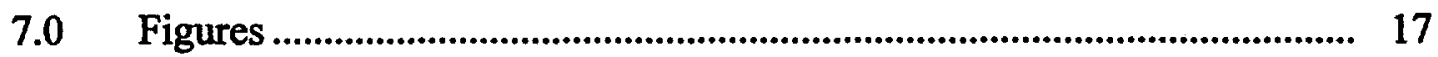




\subsection{Introduction}

DYNA2D ${ }^{1}$ is an explicit Lagrangian finite element code used to model dynamic events where stress wave interactions influence the overall response of the system. DYNA2D is often used to model penetration problems involving ductile-to-ductile impacts with and without material erosion. There are several good ductile damage models available in DYNA2D (Steinberg-Guinan, Johnson-Cook and Bamman/Sandia Damage). However, with the advent of the use of ceramics in the armor-anti-armor community and the need to model damage to laser optics components, good brittle damage models are now needed in DYNA2D. This report details four brittle damage models incorporated into DYNA2D for the use of modeling dynamic impact events with brittle materials such as ceramics and glasses.

The first three brittle damage models described here use a scalar damage parameter to track cumulative damage while the fourth brittle damage model incorporates a tensor damage via the explicit tracking of 3D cracks within an element. Section 2 of this report will describe the scalar damage models, Section 3 will describe the tensor damage model, Section 4 will describe the method used to determine the material and damage parameters for each model, and Section 5 will discuss some concerns when using the various damage models.

\subsection{Scalar Damage Models}

Three scalar damage models have been incorporated into DYNA2D to calculate the brittle damage response of ceramics and glasses. They are 1) Modified Tuler-Butcher Damage Model, 2) Modified Cagnoux-Glenn Brittle Damage Model, and 3) SteinbergTipton Brittle Damage Model. Each of these models have their origin represented by their researchers respected names. The models have been tweaked to combine certain features which seemed relevant to modeling impact problems. The differences between these three models is in the evolution of the scalar damage parameter, $D$. The commonality in the three models is the determination of the deviatoric stresses, pressure, and material property degradation. Material properties are separated into unbroken and broken (failed) material components. The shear modulus, yield strength and pressure are then degraded based on the damage parameter, $D$.

$$
\begin{aligned}
& G=G_{\text {broken }} D+G_{\text {unbroken }}(1-D) \\
& Y=Y_{\text {broken }} D+Y_{\text {unbroken }}(1-D)
\end{aligned}
$$

Two constitutive models for the unbroken material are available, Isotropic-Elastic-Plastic and Steinberg-Guinan High Rate Elastic Plastic.

The Isotropic-Elastic-Plasticconstitutive law includes both strain and pressure hardening. The yield strength is given by: 


$$
\begin{aligned}
& \sigma_{y}=\sigma_{0}+E_{p} \bar{\varepsilon}^{p}+\left(a_{1}+a_{2} p\right) \hat{p} \\
& \hat{p}=\max (p, 0)
\end{aligned}
$$

The Steinberg-Guinan High Rate Elastic Plastic constitutive law includes strain hardening, pressure hardening and thermal softening. The yield strength is given by:

$$
\begin{aligned}
& \sigma_{y}=\sigma_{0}^{\prime}\left[1+b^{\prime} p V^{\frac{1}{3}}-h \frac{E_{i}-E_{c}}{3 R^{\prime}}-300\right] e^{-\frac{f E_{i}}{E_{m}-E_{i}}} \\
& \sigma_{0}^{\prime}=\sigma_{0}\left[1+\beta\left(\gamma_{i}+\bar{\varepsilon}^{p}\right)\right]^{n}
\end{aligned}
$$

The unbroken shear modulus also includes pressure hardening and thermal softening:

$$
G=G_{0}\left[1+b p V^{\frac{1}{3}}-h \frac{E_{i}-E_{c}}{3 R^{\prime}}-300\right] e^{-\frac{\mathrm{fE}_{i}}{E_{m}-E_{i}}}
$$

The broken material yield stress is obtained from tabulated data of yield versus pressure, Figure 1a. Figure $1 \mathrm{~b}$ shows a typical broken yield surface for glass. Under compressive loading the material's yield strength is a function of only pressure with an upper limit on the yield surface. The broken material can not handle any tensile loading. Once the broken yield surface is obtained, the broken shear modulus may be determined:

$$
G_{\text {broken }}=G_{\text {unbroken }}\left(\frac{Y_{\text {broken }}}{Y_{\text {unbroken }}}\right)
$$

A Mie-Gruniesen or Linear Polynomial Equation of State (EOS) is used for the pressure component of both the unbroken and the broken material. The broken material cannot handle any pressure in tension. The phenomenon of bulking (dilatation) can be handled by specifying the reference density of the broken material to some value less than the reference density of the unbroken material. The bulk modulus of the broken material may also be scaled by a user input factor.

An element is considered failed when the damage limit variable, ffail, reaches a user specified value between 0 and 1 (default 0.9 ). At this point, only the broken properties are used and the shear modulus cannot fall below 1-ffail times the unbroken shear modulus. The evolution of the damage parameter, $D$ dictates the degree of failure observed in the material. This is where the three brittle damage models come into play. 


\subsection{Modified Tuler-Butcher Brittle Damage Model}

Tuler and Butcher ${ }^{2}$ developed a criteria for the time dependence of dynamic fracture which has been applied to ductile materials. For brittle materials it is known that the tensile stress needed to propagate a crack decreases with the size of the crack. Therefore, it is assumed that the tensile stress bearing capacity of an element, sometimes referred to as spall strength, decreases while the element is being damaged. Dynamic fracture is a time-dependent phenomena in which the cumulated damage and spall strength depends on the stress pulse duration. In the Tuler-Butcher theory, the condition for fracture can be explained in terms of cumulative damage,

$$
\left(\sigma-\sigma_{\mathrm{c}}\right)^{\lambda} \Delta \mathrm{t}=\mathrm{K}
$$

Applying the concept of cumulative damage leads to the integral form,

$$
\int_{0}^{t_{f}}\left(\sigma-\sigma_{c}\right)^{\lambda} d t=K
$$

where $t_{\mathrm{f}}$ is the fracture time, $\sigma_{\mathrm{c}}$ is the spall strength at time $t, \sigma$ is the current maximum principle stress, and $K$ is a measure of the total cumulated damage. During tensile failure, the maximum principle stress is determined from the maximum of the three principal stresses of the stress state tensor.

$$
\sigma \equiv \max \left(\sigma_{1}, \sigma_{2}, \sigma_{3}\right)>\sigma_{c}
$$

The damage parameter is evolved as:

$$
\begin{aligned}
& \dot{\mathrm{D}}=\frac{1}{\mathrm{~K}}\left(\sigma-\sigma_{\mathrm{c}}\right)^{\mathrm{a}} \\
& \sigma_{\mathrm{c}}=\sigma_{0}(1-\mathrm{D})^{\mathrm{b}} \\
& \mathrm{D}=\mathrm{D}+\dot{\mathrm{D}} \Delta \mathrm{t}
\end{aligned}
$$

where $\sigma_{0}$ is the reference spall strength of intact material, $a$ and $b$ are material constants.

\subsection{Modified Cagnoux-Glenn Brittle Damage Model}

Cagnoux ${ }^{3}$ developed a phenomenological model for the spalling of Pyrex glass impacted at high velocity. This model was modified by Glenn ${ }^{4}$ to include dilitational effects and used to model shaped charge jet penetration in glass. As before (eq. 12), the maximum principle stress is determined from the maximum of the three principle stresses of the stress state tensor. Upon damage initiation a scalar damage parameter $D$ is evolved: 


$$
\dot{\mathrm{D}}=\frac{\left(\sigma-\sigma_{\mathrm{c}}\right)}{\mathrm{B}(1-\mathrm{D})^{\mathrm{b} \sigma}}
$$

where $\sigma_{\mathrm{c}}$ is the spall of intact material, $\sigma$ is the maximumprinciple stress, and $B$ and $b$ are material constants. $D$ is advanced per eq. 15 .

\subsection{Steinberg-Tipton Brittle Damage Model}

This model was developed by Tipton and Steinberg ${ }^{5}$ and implemented in the CALE $^{6}$ hydrodynamics code. Its main usage has been in predicting penetration into ceramics. This model accounts for damage caused by compressive stress, tensile stress, pressure, effective plastic strain and tensile deviatoric stress. Damage progresses from 0 to 1 . Shear modulus, yield stress and pressure degrade from undamaged to fully damaged properties. Once damage starts, it propagates at the bulk sound speed of the material times a factor, $(0<$ frate $<1$, default 0.5$)$. For each failure criterion selected, a critical ratio is formed, squared and summed together.

$$
\begin{aligned}
& \text { fail }=\Sigma\left[\min \left(\frac{f_{\text {type }}}{f_{\text {limit }}}, 0\right)^{2}\right] \\
& \mathrm{f}_{\text {type }}=\left(\text { pressure, eps, } \sigma_{1}, \sigma_{3}, \ldots\right)
\end{aligned}
$$

Whenever the general failure variable, fail exceeds one, the damage parameter $D$ is evolved:

$$
\begin{aligned}
& D=D+\text { frate } \frac{U}{\Delta x} \Delta t \\
& U=\sqrt{\frac{4 G_{0}}{3 \rho}}
\end{aligned}
$$

where frate is a rate multiplier, $\Delta x$ is the characteristic distance across a zone, $\Delta t$ is the time step of the current cycle, and $U$ is the elastic wave speed.

The above three scalar damage models have each been incorporated into DYNA2D as Material Model 27 (Steinberg-Guinan constitutive response) and Material Model 28 (Elastic-Plastic constitutive response).

\subsection{Tensor Damage Model - Modified Rubin/Attia 3D Crack Model}

One tensor damagemodel that has been incorporated into DYNA2D to calculate the brittle damage response of glass is $A$ Continuum Tensile Failure Model With Friction 
developed by Rubin and Attia ${ }^{7}$. A brief description of the model follows. The Cauchy stress $T$ is separated into two parts,

$$
T=T_{u}+T_{v}
$$

where $T_{u}$ is the unfractured stress associated with the elastic-plastic response to deformation and $T_{v}$ is the void stress associated with the response caused by void formation when an element fractures. Fracture is modeled in a continuum sense by introducing a symmetric tensor $\mathrm{e}^{\mathrm{v}}$ which denotes void strain. The void strain is determined by restricting the traction vector that is applied on a fracture surface. The model allows the formation of up to three orthogonal fracture surfaces, which are normal to the right-handed orthonormal set of unit vectors $\left\{\mathrm{n}_{1}, \mathrm{n}_{2}, \mathrm{n}_{3}\right\}$ characterizing the fracture triad. Compressive yielding and tensile failure are each treated separately. Compressive failure involves the evolution of a scalar damage variable and tensile failure involves the formation of three fracture surfaces and the evolution of a void strain. Compressive failure will be discussed first.

Compressive Shear Failure:

There are three possible yield functions that can be used for the unbroken material with this model; 1) yield strength model proposed by Rubin $^{8}, 2$ ) yield strength model proposed by Cherry and Petersen ${ }^{9}$, and 3) Isotropic-Elastic-Plastic with strain and pressure hardening. The first two yield functions have been developed for used with earthen materials and the third yield function is generic in nature and does not require extensive test data to develop working parameters. For each of these yield surface models, the total equivalent yield stress is separated into an unbroken and broken component. In all cases the broken yield surface component is defined as a piece-wise linear yield versus pressure function, Figure 1a. A scalar damage variable, $D$ is used to transition between the broken and unbroken yield curves,

$$
\begin{aligned}
& \text { damage }=\bar{\varepsilon}^{\mathrm{p}}+\mathrm{e}^{\mathrm{v}} \mathbf{k k} \\
& \mathrm{D}=\frac{\text { damage }}{\text { shear_failure_limit }}
\end{aligned}
$$

where $\bar{\varepsilon}^{\mathfrak{p}}$ is the effective plastic strain, $e^{\mathbf{v}} \mathbf{k k}$ is the peak trace of the void strain tensor, and shear failure limit is a user supplied value. The broken shear modulus is defined as some fraction of the original unbroken shear modulus. The shear modulus and yield surface are then determined based on eqs. 1 and 2. Plasticity is limited to the unfractured deviatoric stress $\mathrm{T}_{\mathrm{u}}^{\prime}$ which guarantees that a solution exists that is compatible with both the constraints of plasticity and tensile failure. Pressure is determined from either a Pore Collapse Model or a Linear Polynomial EOS. Once an element group has passed through the shear failure routines, it is then processed for tensile failure. 
Tensile Failure:

The fracture triad (tensile failure) actually describes the right-handed orthonormal triad associated with potential or existing fractures. If the material is unfractured, then the void strain and void stress vanish, and the three vectors $\left\{\mathrm{n}_{1}, \mathrm{n}_{2}, \mathrm{n}_{3}\right\}$ are taken to coincide with the principal directions of $\mathrm{T}$ and ordered so that,

$$
\mathrm{T}_{11} \geq \mathrm{T}_{22} \geq \mathrm{T}_{33}
$$

The material will initiate a single fracture when $T_{11}$ reaches a critical value $T_{f} . T_{f}$ may be defined as a constant or strain rate dependent via a load curve. This single fracture evolves as a material surface until a second fracture is formed. Once the second fracture forms, the fracture triad does not necessarily coincide with the principal directions of stress. The constitutive equations for a fractured surface are:

$$
\begin{aligned}
& \mathrm{T}_{11}=\mathrm{T}_{\mathrm{u} 11}-\left(\lambda_{0}+2 \mathrm{G}_{0}\right) \mathrm{e}^{\mathrm{v}}{ }_{11}-\lambda_{0} \mathrm{e}^{\mathrm{v}}{ }_{22}-\lambda_{0} \mathrm{e}^{\mathrm{v}}{ }_{33} \quad \text { [25] } \\
& \mathrm{T}_{22}=\mathrm{T}_{\mathrm{u} 22}-\lambda_{0} \mathrm{e}^{\mathrm{v}}{ }_{11}-\left(\lambda_{0}+2 \mathrm{G}_{0}\right) \mathrm{e}_{22}^{\mathrm{v}}-\lambda_{0} \mathrm{e}^{\mathrm{v}}{ }_{33} \quad \text { [26] } \\
& \mathrm{T}_{33}=\mathrm{T}_{\mathrm{u} 33}-\lambda_{0} \mathrm{e}^{\mathrm{v}}{ }_{11}-\lambda_{0} \mathrm{e}_{22}^{\mathrm{v}}-\left(\lambda_{0}+2 \mathrm{G}_{0}\right) \mathrm{e}^{\mathrm{v}}{ }_{33} \\
& \mathrm{~T}_{12}=\mathrm{T}_{\mathrm{u} 12}-2 \mathrm{G}_{0} \mathrm{e}_{12}^{\mathrm{v}} \\
& T_{13}=T_{u 13}-2 G_{0} e^{v} v_{13} \\
& \mathrm{~T}_{23}=\mathrm{T}_{\mathrm{u} 23}-2 \mathrm{G}_{0} \mathrm{e}^{\mathrm{v}} 23
\end{aligned}
$$

Based on the number of fractures, equations 25-30 are used to solve for the diagonal components of the void strains.

The off diagonal components of void strain are determined by evolution equations for their rates. A Mohr-Coulomb friction condition is used to determine the magnitude of the shear stress applied on the fracture surface.

$$
\tau_{1}^{2}=\left(\mathrm{T}_{12}\right)^{2}+\left(\mathrm{T}_{13}\right)^{2}
$$

This shear stress value is limited by the maximum allowable value $\tau_{\mathrm{f}}$, which is determined by the normal stress $T_{11}$ applied on the fracture surface such that,

$$
\tau_{\mathrm{fl}}=-\mu_{\mathrm{f}} \mathrm{T}_{11}
$$

where $\mu_{\mathrm{f}}$ is the constant friction coefficient.

The above tensor damage model has been incorporated into DYNA2D as Material Model 29. 


\subsection{Determination of the Material and Damage Parameters}

Three types of problems were chosen to evaluate the brittle damagemodels. The first example is a rigid body penetrator through Float glass. The residual velocity of the penetrator is used as the measure of correctness of the damage models. This problem can be modeled without the need to erode or delete elements from the problem. Key features of the damage models needed to solve this class of problems are the failed material response and the use of the material bulking phenomena. The second example problem is the penetration of a Tungsten rod into Pyrex which is backed with 4340 steel. Residual penetration into the steel is used as the measure of correctness of the damage models. Erosion of the penetrator, glass and steel backing occurs. Erosion in DYNA2D is handled by element deletion based on some failure criteria. The choice and magnitude of this criteria can add to the complexity of the problem. The final example problem will be a small hardened steel ball impact on the surface of fused silica glass. This problem requires a more detailed tracking of the evolution of damage and/or cracking that is observed in experiments.

For each of the example problems, the same constitutive model, Elastic-Plastic, was used with a Mie-Gruneisen EOS. EOS parameters for glass were obtained from data of Wackle ${ }^{10}$. The dynamic yield stress and spall stress are determined from the Hugoniot Elastic Limit (HEL) and the Poisson's Ratio. Table 1 shows the mechanical properties used for the unbroken glass materials. All of the glasses utilized the same EOS parameters, Table 2. The determination of damage parameters for the various models is achieved by matching damage phenomena and key results observed in experiments.

Table 1: Mechanical Properties for Unbroken Glass

\begin{tabular}{|l|c|c|c|}
\hline Parameter & $\begin{array}{c}\text { Float } \\
\text { Glass }\end{array}$ & Pyrex & Fused Silica \\
\hline Density (gm/cm ${ }^{3}$ ) & 2.7 & 2.23 & 2.203 \\
\hline Poisson's Ratio & 0.227 & 0.2 & 0.17 \\
\hline Shear Modulus (Mbar) & 0.267 & 0.267 & 0.315 \\
\hline Dynamic Yield Strength (Mbar) & 0.040 & 0.050 & 0.0525 \\
\hline Tangent Modulus (Mbar) & 0.001 & 0.001 & 0.001 \\
\hline
\end{tabular}


Table 2: Equation of State Parameters for Glass

\begin{tabular}{|l|c|l|c|}
\hline Mie-Gruneisen & $\begin{array}{c}\text { Mie- } \\
\text { Gruneisen }\end{array}$ & $\begin{array}{c}\text { Linear } \\
\text { Polynomial }\end{array}$ & $\begin{array}{c}\text { Linear } \\
\text { Polynomial }\end{array}$ \\
\hline $\mathrm{C}(\mathrm{cm} / \mu \mathrm{s})$ & 0.435 & $\mathrm{C} 0$ (Mbar) & 0 \\
\hline S1 & 0.3 & $\mathrm{C} 1$ (Mbar) & 0.4167 \\
\hline S2 & 0 & $\mathrm{C} 2$ (Mbar) & -0.1748 \\
\hline S3 & 0 & $\mathrm{C} 3$ (Mbar) & 0.0405 \\
\hline gamma & 0.039 & $\mathrm{C} 4$ & 0.039 \\
\hline a & 0.0 & $\mathrm{C} 5$ & 0.0 \\
\hline E0(Mbar-cc/cc) & 0.0 & $\mathrm{C} 6$ & 0.0 \\
\hline V0 & 1.0 & E0 (Mbar-cc/cc) & 0.0 \\
\hline & & V0 & 1.0 \\
\hline
\end{tabular}

\subsection{Rigid Body Penetration Through Float Glass}

Pavel ${ }^{11}$ performed rigid body penetration experiments into Float glass. The projectile was $1.3 \mathrm{~cm}$ diameter by $4.1 \mathrm{~cm}$ long with an ogive nose and made of tungsten carbide, mass $=68.9$ grams. The target was $15 \mathrm{~cm}$ diameter by $7.0 \mathrm{~cm}$ long Float glass with a density of $2.7 \mathrm{~g} / \mathrm{cm}^{3}$ and no confinement. The projectile impacted the glass at a velocity of $1.06 \mathrm{~km} / \mathrm{s}$ and normal incidence. The residual velocity was measured at $0.8 \mathrm{~km} / \mathrm{s}(\mathrm{Vi} / \mathrm{Vr}=0.75)$. For this analysis the Modified Tuler-Butcher and Modified Cagnoux-Glenn brittle damage models were used. Figure 2 shows the initial DYNA2D set-up, while Table 3 shows the parameters used for the Modified Tuler-Butcher model analyses, and Table 4 shows the parameters used for the Modified Cagnoux-Glenn model analyses. The projectile was modeled as an elastic material. A small pin hole on the symmetry plan was used to allow the glass material to flow around the projectile. Glass elements were not allowed to be deleted; however, periodic rezoning was necessary to prevent excessive element distortion.

Table 3: Modified Tuler-Butcher Parameters for Rigid Penetrator Analysis

\begin{tabular}{|l|l|l|l|l|}
\hline Parameters & Case 1 & Case 2 & Case 3 & Case 4 \\
\hline sig $_{0}$ (Mbar) & 0.0038 & 0.0038 & 0.0038 & 0.0038 \\
\hline K(Mbar-us) & $4.89 \mathrm{e}-3$ & $4.89 \mathrm{e}-3$ & $5.5 \mathrm{e}-4$ & $5.5 \mathrm{e}-4$ \\
\hline $\mathrm{a}$ & 1 & 1 & 1 & 1 \\
\hline $\mathrm{b}$ & 3 & 3 & 3 & 3 \\
\hline ffail & 0.9 & 0.9 & 0.9 & 0.9 \\
\hline feta & 1.0 & 1.0 & 0.98 & 0.95 \\
\hline fbulk & 1.0 & 1.0 & 1.0 & 1.0 \\
\hline failure slope & 0.8 & 0.8 & 0.8 & 0.8 \\
\hline sigf(Mbar) & 0.030 & 0.015 & 0.030 & 0.030 \\
\hline Vr/Vi & 0.73 & 0.74 & 0.77 & 0.49 \\
\hline
\end{tabular}


Table 4: Modified Cagnoux-Glenn Parameters for Rigid Penetrator Analysis

\begin{tabular}{|l|l|l|l|}
\hline Parameters & Case 5 & Case 6 & Case 7 \\
\hline sigc (Mbar) & 0.0038 & 0.0038 & 0.0038 \\
\hline B (Mbar-us) & $7.0 \mathrm{e}-8$ & $7.0 \mathrm{e}-10$ & $7.0 \mathrm{e}-10$ \\
\hline b (Mbar & 700 & 700 & 700 \\
\hline ffail & 0.9 & 0.9 & 0.9 \\
\hline feta & 1.0 & 1.0 & 0.98 \\
\hline fbulk & 1.0 & 1.0 & 1.0 \\
\hline failure slope & 0.8 & 0.8 & 0.8 \\
\hline sigf(Mbar) & 0.030 & 0.030 & 0.030 \\
\hline Vi/Vr & 0.68 & 0.72 & 0.73 \\
\hline
\end{tabular}

Figures 3 and 4 show the penetration at 20 and 100 microseconds, respectively for Case 1 . The plots fringe the damage variable $D$, where the red signifies completely failed material capable of handling only compressive loading. A large damage zone precedes the penetrator due to the elastic wave speed in glass being $5 \mathrm{~km} / \mathrm{s}$ and the dispersive nature of the loading. This large damage zone indicates that the precise detail of the damage evolution is not as important as the response of the failed material. For materials that exhibit bulking (some glasses and ceramics), the use of this feature can significantly influence the results. Figures 5 and 6 show the penetration at 100 microseconds for Case 3 and Case 4, respectively. This illustrates the sensitivity to bulking of the failed material. Case 3 had 2\% bulking while Case 4 had 5\% bulking. The increased pressure caused by bulking enlarged the damaged area, but also decreased the projectile velocity. Figure 7 shows the time history of velocity of the projectile for Cases 1-4. There was only a slight difference in the residual velocity when adjusting the maximum failed yield surface from 15 to $30 \mathrm{kbars}$ (Case 1 vs. Case 2). The inclusion of bulking caused increase resistance to penetration.

Figures 8 and 9 shows the penetration at 100 microseconds for Cases 5 and 6 , respectively, indicating the sensitivity to the damage parameter $B$. Figure 10 illustrates the effect of bulking used with the Modified Cagnoux-Glenn Model. The 2\% bulking used with the Modified Cagnoux-Glenn Model, Case 7, has a more drastic effect on the overall damage of the glass than $2 \%$ bulking with the Modified Tuler-Butcher Model, Case 3. Figure 11 shows the time history of velocity of the projectile for Cases 5-7. The inclusion of bulking causes the projectile to decelerate more quickly. For this class of problems, the more complicated and expensive models are not necessary.

\subsection{Tungsten Rod Penetration in Pyrex/4340 Steel}

Reaugh ${ }^{12}$ performed an experimental study of Tungsten rods penetrating into Pyrex. The experimental set-up consisted of a Pyrex block of various lengths placed against a block of 4340 steel. The Pyrex was impacted by a Tungsten alloy rod and the residual penetration into the 4340 steel block was measured. The velocity of the Tungsten rods were varied along with the thickness of the Pyrex blocks. To model this experiment, the Lagrangian analysis code must have an eroding material capability. DYNA2D has such 
a capability where the erosion is handled by deleting elements from the analysis while allowing automatic contact to handle the material interfaces. For ductile penetration problems, the main element failure criteria is effective plastic strain; however, for brittle materials, this may not be appropriate. In some cases the communed material exhibits bulking and one would want that material to remain in front the penetrator as long as possible. Several element deletion criteria have been incorporated into the brittle damage models. Effective plastic strain is one criteria; however this may be reached very quickly since ceramics and glasses exhibit very little plastic flow. Arbitrarily large value of effective plastic strain may be necessary for glasses and ceramics. Another deletion criteria is to limit the element distortion for completely failed elements, either by a volumetric strain criteria or a minimum angle criteria, thus allowing them to remain in the analysis as long as possible. In either case, an element cannot be deleted until it has fully failed $(D=1)$. DYNA2D also has the capability to delete any element that reduces the time step to some factor below the initial time step. Care must be used in selecting when an element is deleted from the analysis. This adds to the complexity of determining damage parameters for a given brittle damage model.

Prior to performing the glass erosion analysis, a separate erosion analysis of a Tungsten rod into 4340 steel was performed to determine the correct element deletion criteria for the Tungsten and 4340 steel. With the deletion parameters set for the Tungsten and the 4340 steel, one can begin to look at the deletion parameters for glass necessary to match experimental results.

Figure 12 is the DYNA2D set-up to model a Tungsten rod penetrating through Pyrex and into 4340 steel. The Tungsten projectile was $0.635 \mathrm{~cm}$ diameter by $2.54 \mathrm{~cm}$ long $(\mathrm{L} / \mathrm{D}=4)$. The Pyrex cylinder was $12 \mathrm{~cm}$ diameter by $4.64 \mathrm{~cm}$ long. The 4340 steel backup plate was $16 \mathrm{~cm}$ diameter by $5.0 \mathrm{~cm}$ long. The Tungsten rod impacted the Pyrex at $1.78 \mathrm{~km} / \mathrm{s}$ with normal incidence. The residual penetration into the 4340 steel was measured at $0.67 \mathrm{~cm}$. For this analysis, the Modified Cagnoux-Glenn and Modified TulerButcher brittle damage models were used. Table 5 shows the parameters used for each damage model.

Table 5: Modified Tuler-Butcher and Modified Cagnoux-Glenn Parameters for Tungsten / Pyrex / Steel Penetrator Analysis

\begin{tabular}{|l|l|l|l|}
\hline Cagnoux-Glenn & Case 8 & Tuler-Butcher & Case 9 \\
\hline sigc (Mbar) & 0.0039 & sig $_{0}$ (Mbar) & 0.0038 \\
\hline B (Mbar-us) & $7.0 \mathrm{e}-8$ & $\mathrm{~K}$ (Mbar-us) & $5.5 \mathrm{e}-4$ \\
\hline $\mathrm{b}$ (Mbar ${ }^{-1}$ ) & 700 & $\mathrm{a}$ & 1 \\
\hline & & $\mathrm{b}$ & 3 \\
\hline ffail & 0.9 & ffail & 0.9 \\
\hline feta & 0.99 & feta & 0.98 \\
\hline fbulk & 1.0 & fbulk & 1.0 \\
\hline failure slope & 0.8 & failure slope & 0.8 \\
\hline sigf (Mbar) & 0.030 & sigf (Mbar) & 0.030 \\
\hline Deletion Strain & 2.0 & Deletion Strain & 2.0 \\
\hline $\begin{array}{l}\text { Residual } \\
\text { Penetration (cm) }\end{array}$ & 0.70 & $\begin{array}{l}\text { Residual } \\
\text { Penetration (cm) }\end{array}$ & 0.55 \\
\hline
\end{tabular}


Figures 13 and 14 show the Tungsten rod penetration at 10 and 60 microseconds, respectively for Case 8 . The plots fringe the damage variable $D$, where the red signifies completely failed material. Damage planes propagate down and out from the center in the Pyrex. The Tungsten rod is fully consumed by the Pyrex and steel. An arbitrarily large amount of plastic strain was used as an element deletion criteria (200\%). A reflected shock off the Pyrex/steel interface is observed and causes early failure near that interface. Figure 15 shows the Tungsten rod penetration at 60 microseconds after impact (Case 9). Very similar damage patterns are observed for the two damage models. The bulking of the failed glass material tends to fill the hole generated from the Tungsten rod.

In general, penetration/erosion problems with Lagrangian codes tend to underpredict hole diameter. This is caused by element deletions in the nose of the penetrator and its inability to form a mushroom shape as observed in experimental x-rays. Depth of penetration can be determined accurately by dialing-in on the necessary element deletion criteria.

\subsection{Steel Sphere Impacts Onto Fused Silica Glass}

The final test of the damage models was to look at a problem were the directionality of the damage is more critical in matching experimental results. A steel sphere impacting a glass surface was used. Curran ${ }^{10}$ performed steel BB gun impacts onto fused silica over a velocity range of $150-300 \mathrm{~m} / \mathrm{s}$. A hardened 440 Stainless steel sphere, $0.05 \mathrm{~cm}$ diameter impacted against an optical quality fused silica glass surface at $305 \mathrm{~m} / \mathrm{s}$. The damage morphology was a hemispherical sub-surface fracture region surrounded by smaller, heavily fractured inner "plastic" region, and in some cases with a few Herzian cone cracks extending somewhat further into the target. The measured outer fracture diameter was $0.165 \mathrm{~cm}$, the inner more fractured region had a diameter of $0.08 \mathrm{~cm}$, and the depth of the fractured region was $0.10 \mathrm{~cm}$.

The DYNA2D set-up for this analysis is shown in Figure 16. A non-reflecting boundary was used on the lower and outer surfaces of the glass. For this class of problems, the $3 D$ Crack Damage Model was used for its capability to better track directional damage. Table 6 lists the parameters used for the 3D Crack Model.

Table 6: 3D Crack Model Parameters for Steel Ball/Fused Silica Impact Analysis

\begin{tabular}{|l|l|}
\hline Parameters & Case 10 \\
\hline G (Mbar) & 0.3152 \\
\hline Y (Mbar) & 0.0525 \\
\hline Shear_Fail_Limit & 0.1 \\
\hline Tensile Limit & 0.00546 \\
\hline Friction & 0.3 \\
\hline Shear_Degrade & 0.333 \\
\hline failure slope & 0.8 \\
\hline sigf (Mbar) & 0.030 \\
\hline
\end{tabular}


An Elastic-Plastic constitutive model using total stress was employed. The Shear Modulus was allowed to degrade to $33 \%$ of the original value as the glass yielded in compression. A friction coefficient of 0.3 was used on the tensile crack surfaces. A constant tensile failure limit of $0.00546 \mathrm{Mbar}$ was used (the model has the capability to define a load curve defining tensile failure limit as a function of strain rate). Case 10, Figure 17 shows the steel ball impact analysis at 80 microseconds after impact. The plot is an element fringe plot of the type of damage in each element. Values of -3 to -1 are the number of tensile cracks, 1 means virgin material, 2 means yielded material, and 3 means failed in compression material. Strong evidence of Herzian cone cracks are observed on the plot as is the compressive "plastic" fracture region beneath the steel ball. The conical crack grow at a semi-apex angle of $30^{\circ}$ then moves horizontal. Experimental steel ball impacts ${ }^{12}$ into Pyrex and Float glass indicate that the cone angle is dependent on the impact velocity. For an impact velocity of $250 \mathrm{~m} / \mathrm{s}$ the experimentally measured cone angle was $30^{\circ}$. The maximum fracture diameter is $0.162 \mathrm{~cm}$ as compared to the experimental value of $0.165 \mathrm{~cm}$. The inner "plastic" fracture region is $0.07 \mathrm{~cm}$ in diameter $\mathrm{cm}$ as compared to the experimental value of $0.08 \mathrm{~cm}$. The depth of the damage is 0.05 $\mathrm{cm}$ indicating a less than hemispherical damage region. Significant yielding of the steel ball (33\% plastic strain) takes place.

For comparison purposes, the Modified Cagnoux-Glenn Model was used with the parameters listed in Table 7.

Table 7: Modified Cagnoux-Glenn Parameters for

Steel Ball/Fused Silica Impact Analysis

\begin{tabular}{|l|l|}
\hline Parameters & Case 11 \\
\hline sigc (Mbar) & 0.0039 \\
\hline B (Mbar-us) & $7.0 \mathrm{e}-8$ \\
\hline b (Mbar ${ }^{-1}$ ) & 700 \\
\hline ffail & 0.5 \\
\hline feta & 0.98 \\
\hline fbulk & 1.0 \\
\hline failure slope & 0.8 \\
\hline sigf (Mbar) & 0.030 \\
\hline
\end{tabular}

Case 11, Figure 18 shows the analysis at 80 microseconds after impact. The plot shows element fringed of the damage parameter $D$ with the red indicating completely failed material. The strong Herzian cone cracks at $30^{\circ}$ are not evident; however, there are some signs of conical cracks emanating from the damage region. The Shear Modulus was not allowed to degrade as much as in the previous examples $(f f a i l=0.5)$ and it still was not enough to cause significant deformation in the steel ball (5\% plastic strain). The outer damaged region is $0.12 \mathrm{~cm}$ diameter and the depth is $0.075 \mathrm{~cm}$. A more hemispherical damage region is observed with this model; however this may be enhanced by the total depth of the steel ball penetration. The overall response of the steel ball/glass interaction does not compare as well to the experiments as compared to the analysis using the $3 D$ Crack Model. 


\subsection{Comments Concerning the Use of the Various Damage Models}

It is important that the appropriate damage model is used for the type of analysis that is required. The cost to employ the tensor damage model is approximately $50 \%$ over a scalar damage model. Bulk glass damage and penetration type problems are solved very efficiently with a scalar damage model. Problems which are dependent of the orientation of crack surfaces are best solved with a tensor damage model.

When it comes to rezoning with DYNA2D, it is important that one understands how DYNA2D remaps the damage parameters. For the three scalar damage models, the damage parameter $D$ and all other state variables are found by interpolation from nodal quantities. This interpolation operation will impart some diffusion of the damaged elements, but should not significantly change the results. When using the tensor damage model, the damaged element state (number of cracks and orientation) is stored as an integer value and not a continuous function. When remapping occurs, this integer state variable is averaged at the nodes. Upon returning from a rezoning operation the constitutive model attempts to redefine the number of cracks and void strains; however some previously cracked elements may be lost. This situation may be minimized by making sure you have adequate mesh resolution and minimizing the number of rezones. At this time the ALE capabilities of DYNA2D cannot be used with the tensor damage model.

Results from the Steinberg-Tipton Brittle Damage Model have purposely been neglected due to unsatisfactory results. This model was added to DYNA2D to have comparable capabilities as CALE. The CALE implementation offers the ability to average the damage criteria over the eight neighboring elements thereby smoothing the damage region. This capability is not included with the DYNA2D implementation; and, as a result, when an element damages, it causes adjacent elements to damage as well. The overall result is that too much damage is observed in the glass. Work needs to be done on this damage model to allow for the element averaging scheme. 
References:

1 Whirley, R.G., Englemann, B.E., and Hallquest, J. O, DYNA2D A Nonlinear, Explicit, Two-Dimensional Finite Element Code For Solid Mechanics User Manual, LLNL UCRL-MA-110630, April, 1992

2 Tuler, F.R., and Butcher, B. M., A Criterion for the Time Dependence of Dynamic Fracture, Int. J. Fracture Mechanics, Vol. 4, No. 4, December 1968.

3 Cagnoux, J, Phenomenological Model of Pyrex Glass Fracture, , J. De Physique, Col C5, suppl au no. 8, Tome 46, 1984

4 Glenn, L.A., Moran, B., and Kusubov, A.S., Modeling Jet Penetration in Glass, LLNL UCRL-JC-103512, April 5, 1992

5 Steinberg, D. J., and Tipton, R. E., A New Fracture Model for Ceramics, LLNL UCRL-JC-116953, March 14, 1994

6 Tipton, R, CALE Users Manual, January 1, 1996

7 Rubin, M.B., and Attia, A.V., A Continuum Tensile Failure Model With Friction, LLNL UCRL-ID-104759, August 21, 1990

8 Rubin, M.B., A Simple and Convenient Isotropic Failure Surface, LLNL UCRL102556, 1989

9 Cherry, J.T., and Petersen, F.L., Numerical Simulation of Stress Wave Propagation From Underground Nuclear Explosions, LLNL UCRL-72216, 1970

10 J. Wackerle, Shock-Wave Compression of Quartz, J. Appl. Phys., 33, p.922, 1962

11 Curran, D., Erlich, D., and Tokheim, B., Damage Algorithms for NIF First Wall, Debris Shield and Beam Dump Materials, SRI, June 1996

12 Knight, C.G., Swain, M.V., and Chaudhri, M.M., Impact of Small Steel Spheres on Glass Surfaces, J. of Material Sciences, Vol. 12, pp. 1573-1586, 1977 


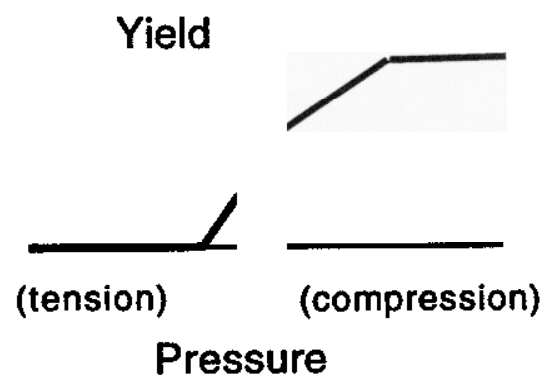

(a)

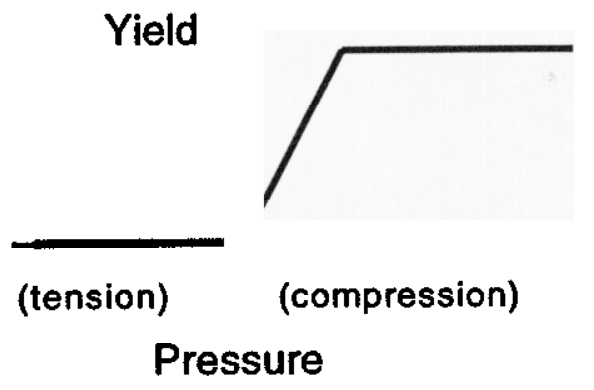

(b)

Figure 1: Broken Material Yield Surface Definition: (a) Piece-wise Linear Definition. (b) Definition for glass

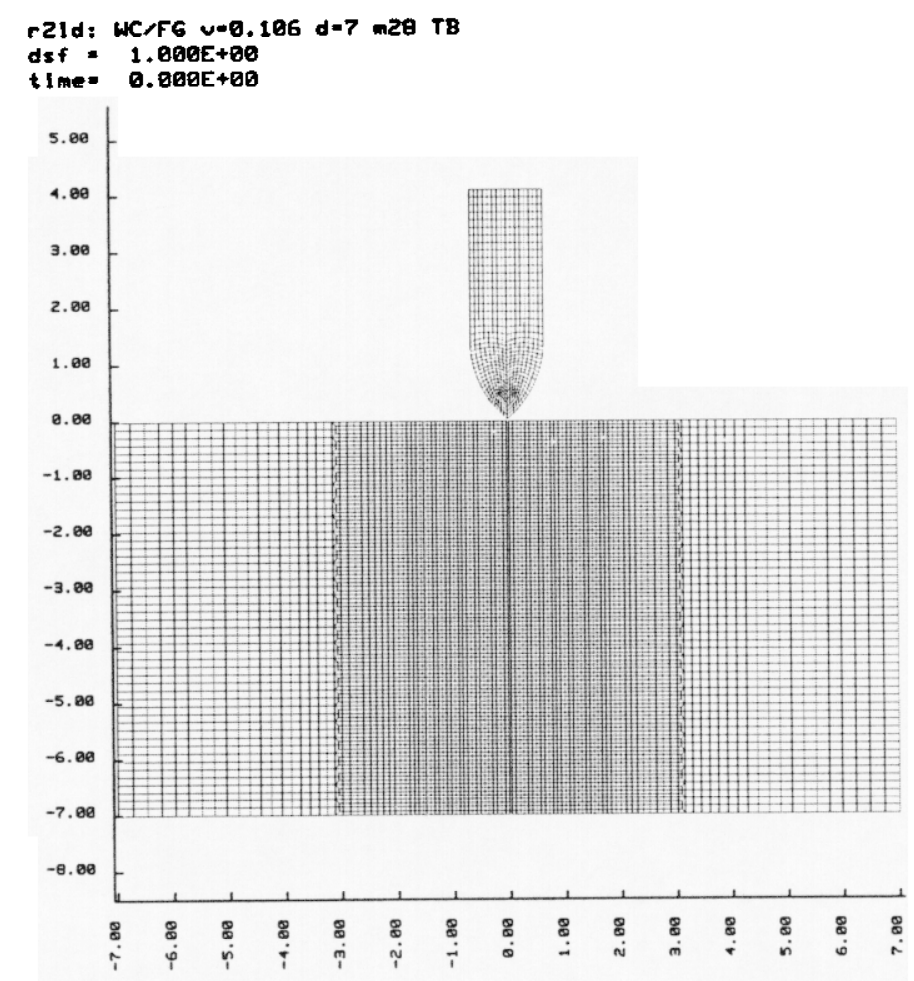

Figure 2: DYNA2D Set-up For Rigid Body Penetration Into Float Glass 


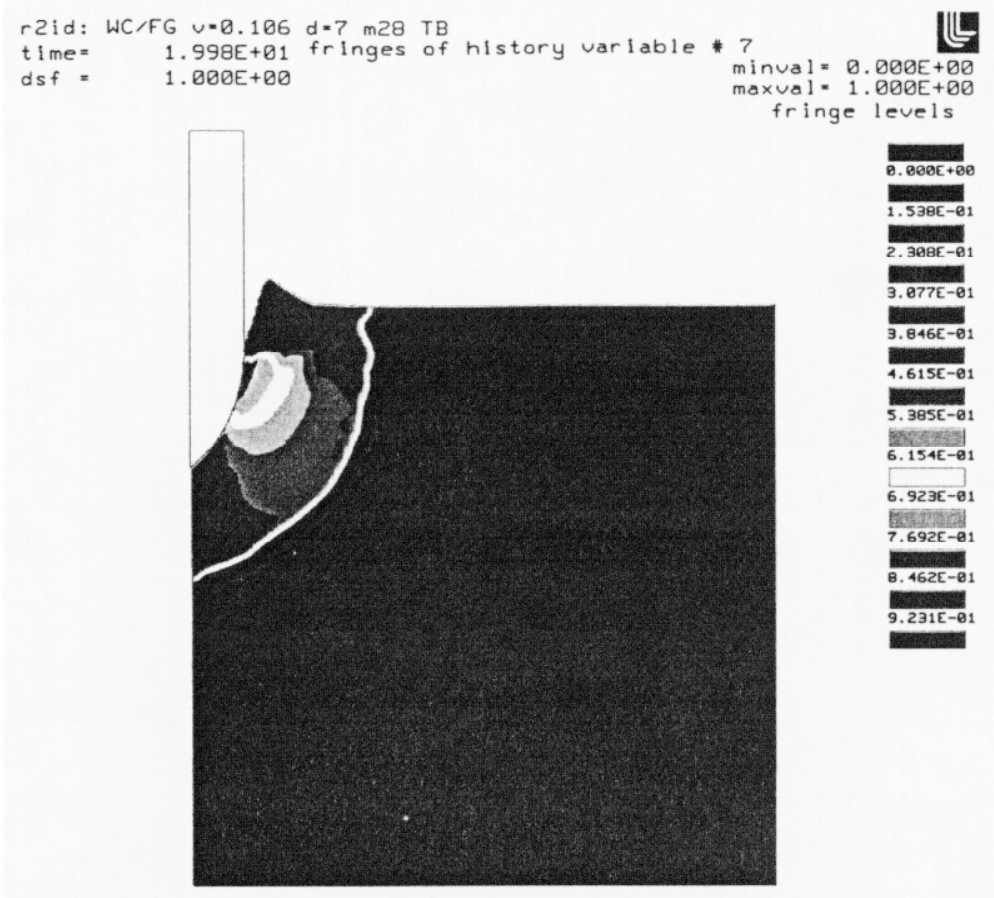

Figure 3: Rigid Body Penetration Into Float Glass - 20 microseconds: Modified TulerButcher Model (Case 1): Fringe of Damage, 1 = Completely Failed

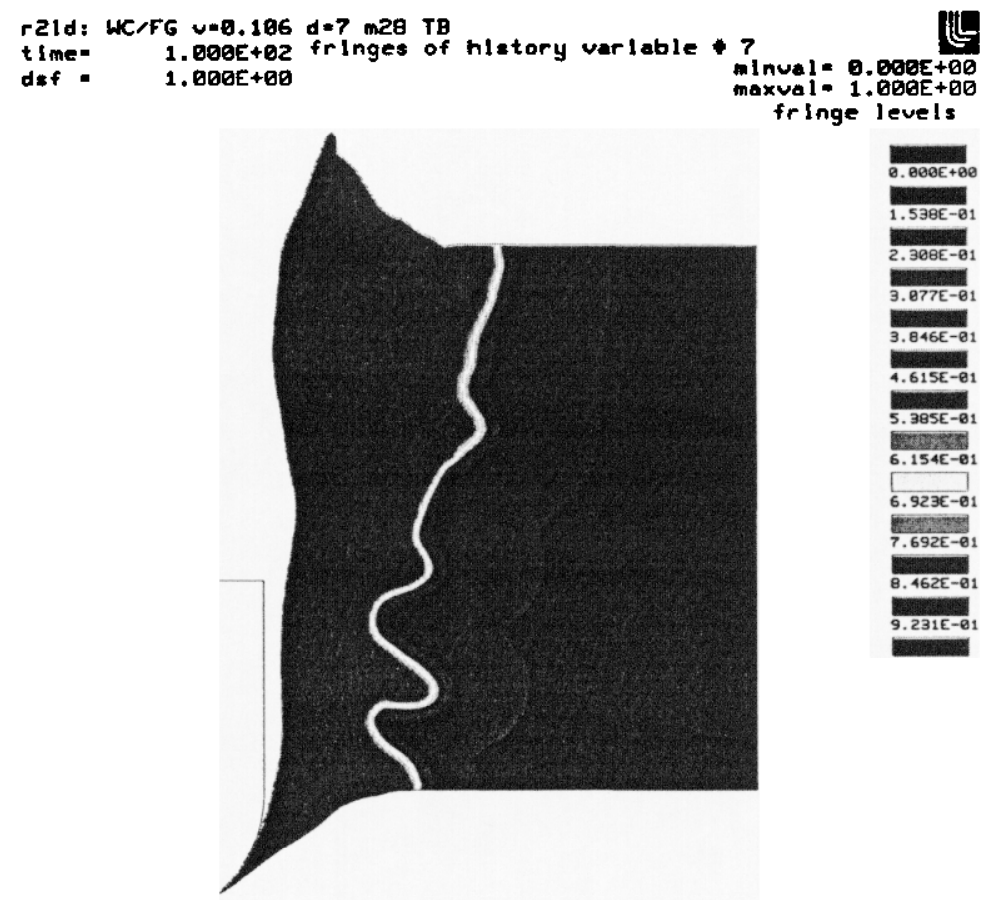

Figure 4: Rigid Body Penetration Into Float Glass - 100 microseconds: Modified TulerButcher Model (Case 1): Fringe of Damage, 1 = Completely Failed 


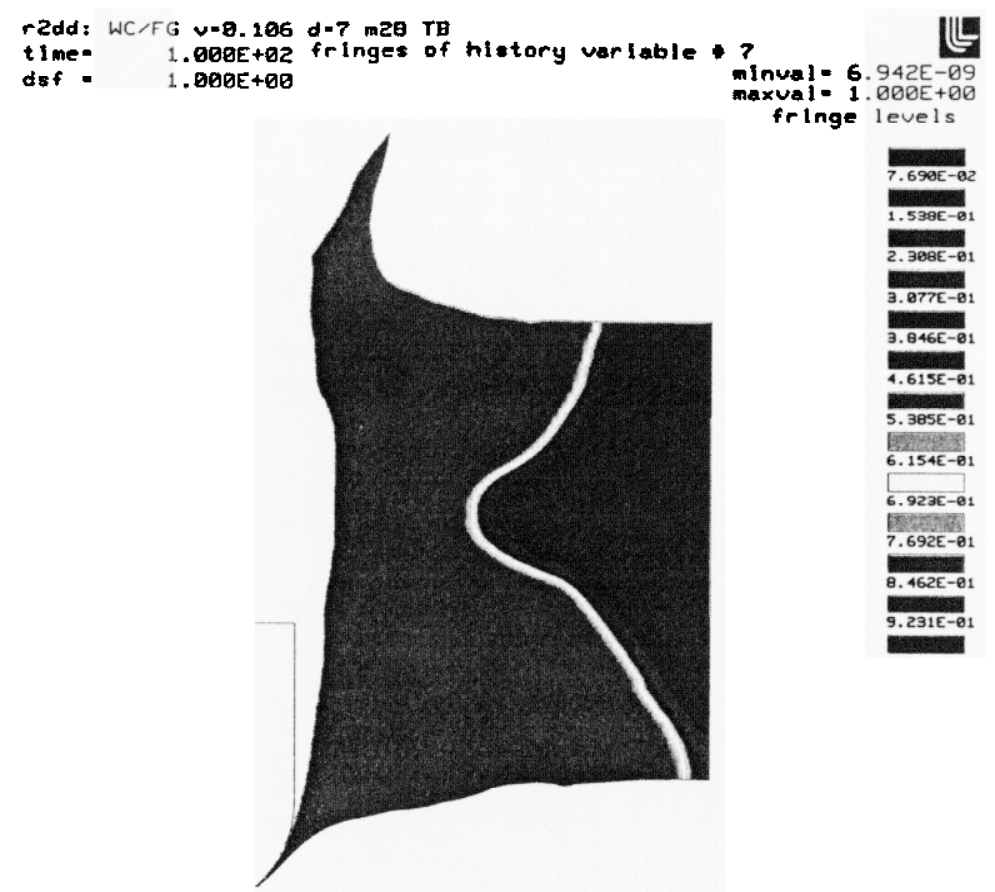

Figure 5: Rigid Body Penetration Into Float Glass - 100 microseconds: Modified TulerButcher Model (Case 3): Fringe of Damage, 1 = Completely Failed

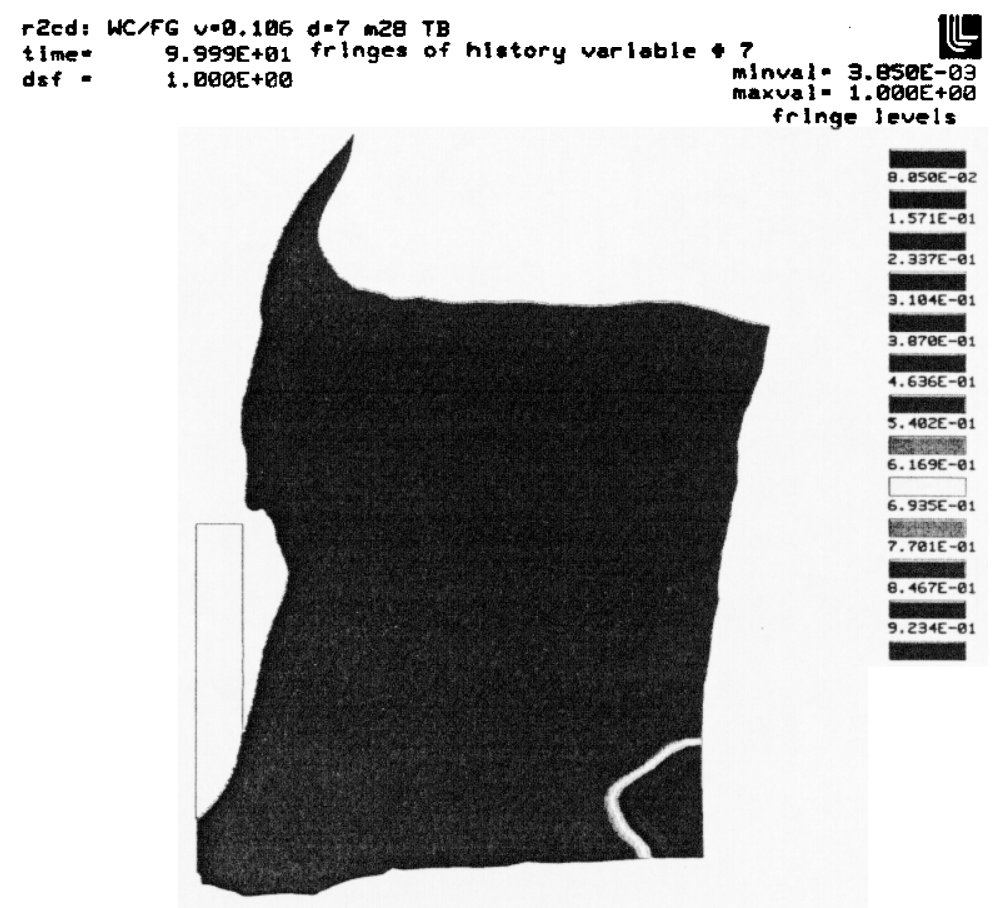

Figure 6: Rigid Body Penetration Into Float Glass - 100 microseconds: Modified TulerButcher Model (Case 4): Fringe of Damage, 1 = Completely Failed 


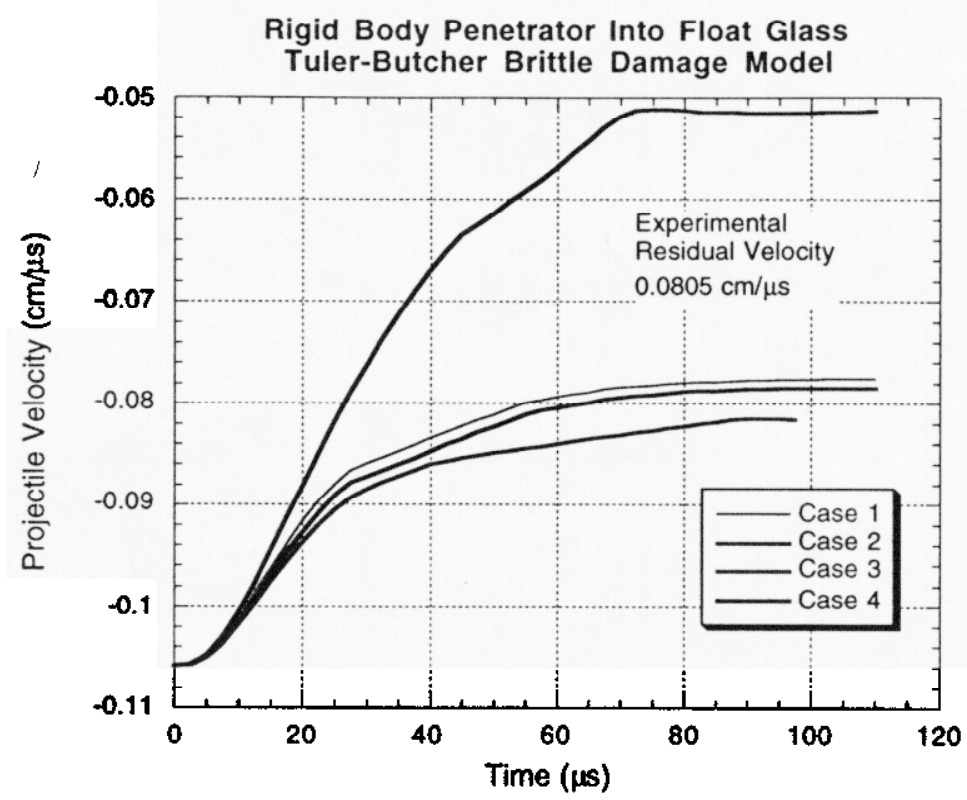

Figure 7: Rigid Body Penetration Into Float Glass : Modified Tuler-Butcher Model: Penetrator Velocity

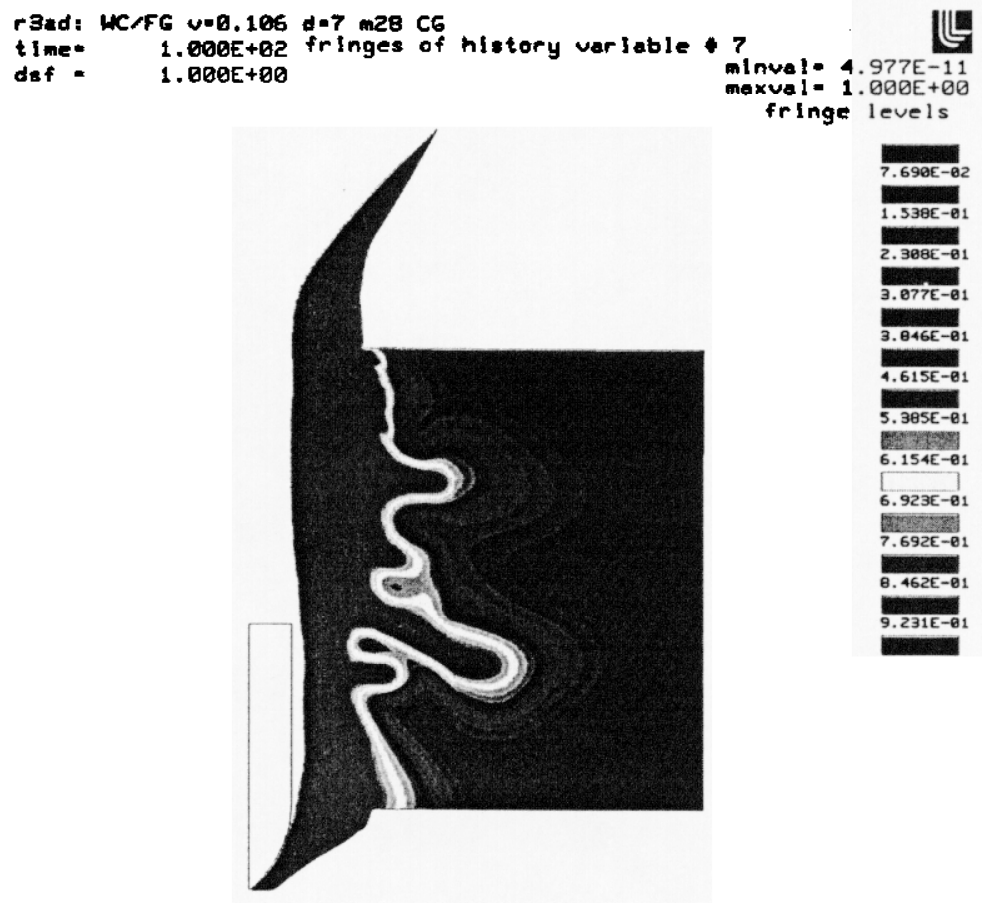

Figure 8: Rigid Body Penetration Into Float Glass - 100 microseconds: Modified Cagnoux-Glenn Model (Case 5): Fringe of Damage, 1 = Completely Failed 


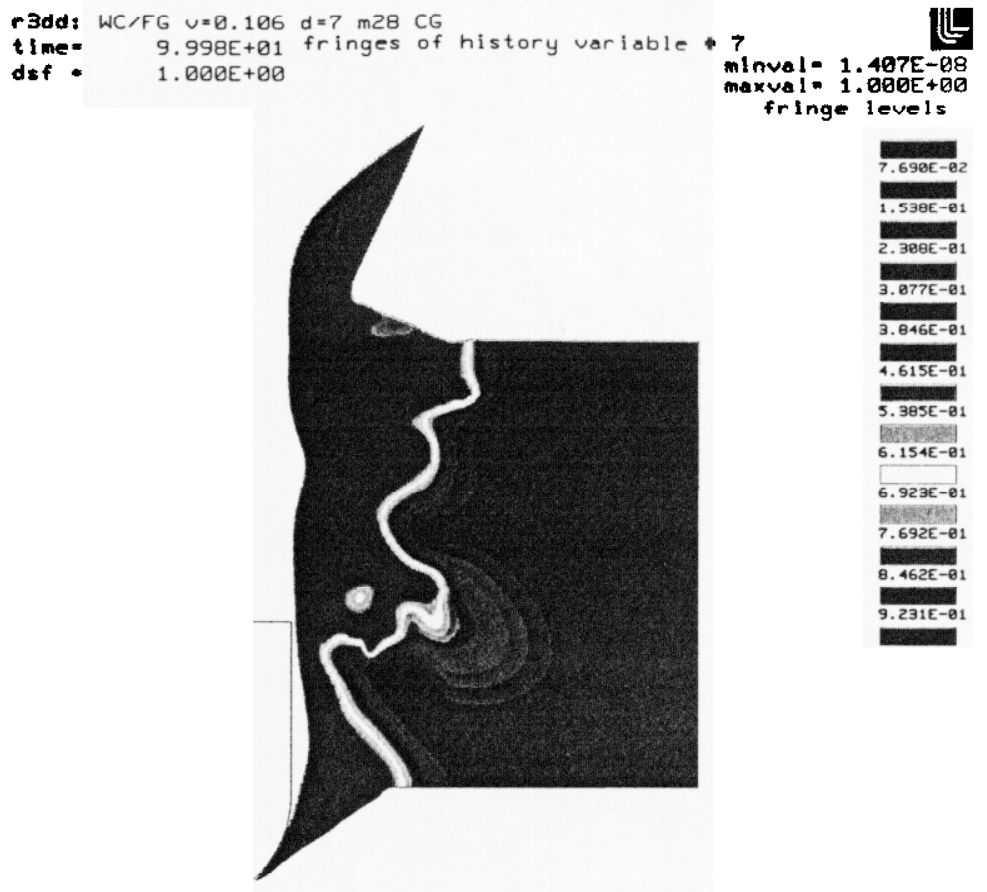

Figure 9: Rigid Body Penetration Into Float Glass - 100 microseconds: Modified Cagnoux-Glenn Model (Case 6): Fringe of Damage, 1 = Completely Failed

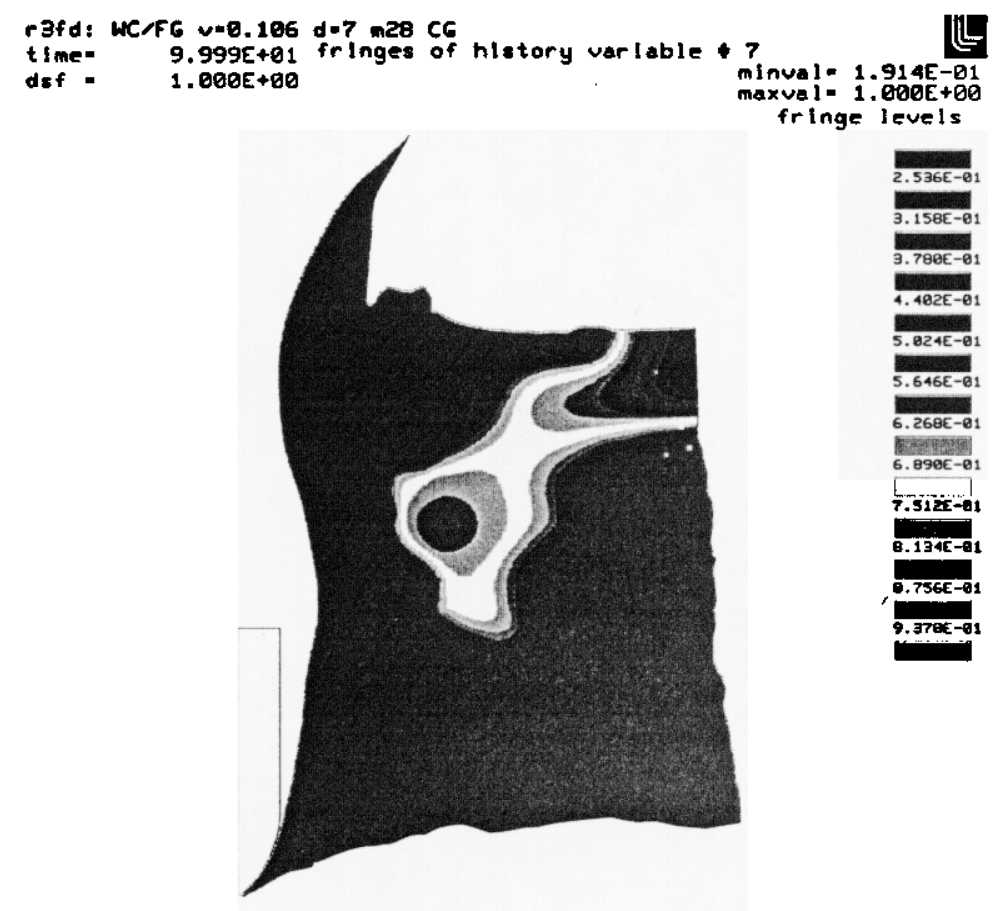

Figure 10: Rigid Body Penetration Into Float Glass - 100 microseconds: Modified

Cagnoux-Glenn Model (Case 7): Fringe of Damage, 1 = Completely Failed 


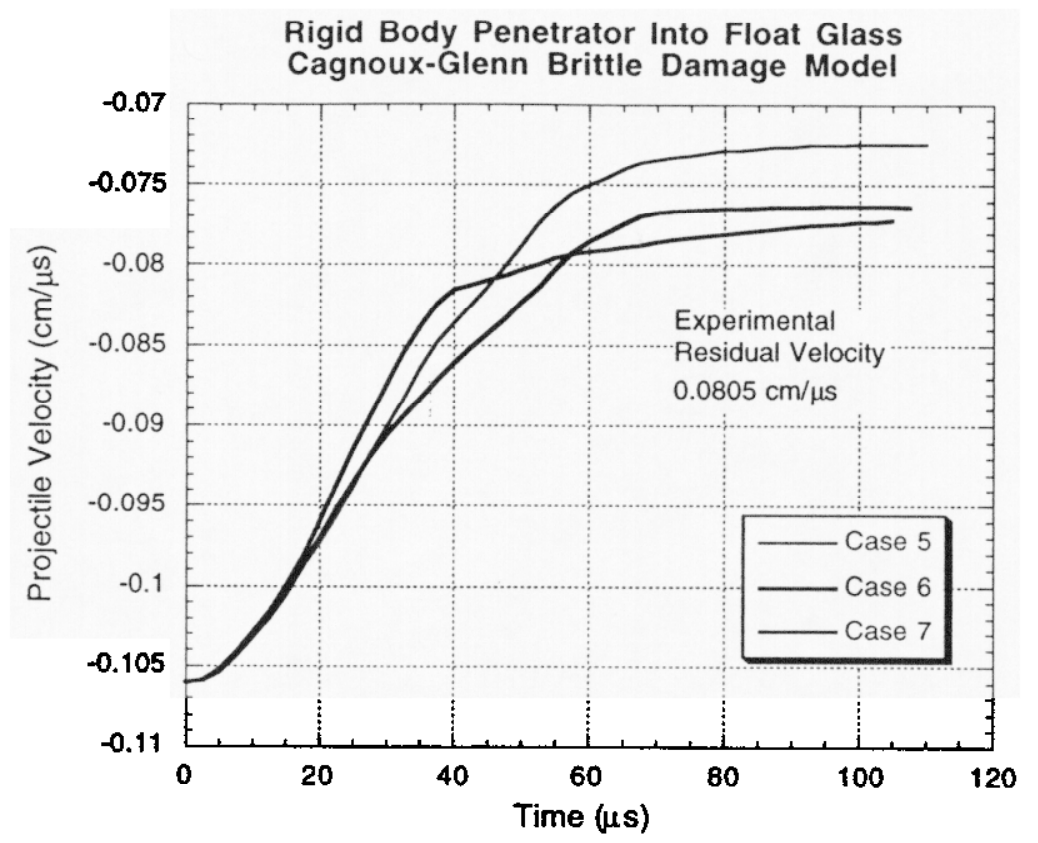

Figure 11: Rigid Body Penetration Into Float Glass: Modified Cagnoux-Glenn Model: Penetrator Velocity

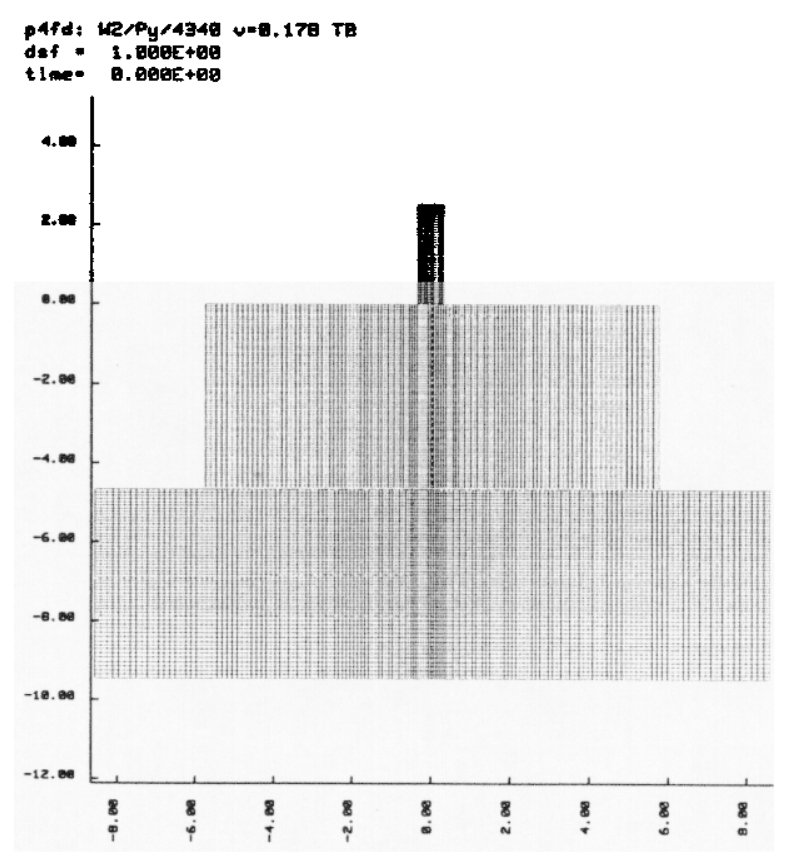

녀

Figure 12: Tungsten/Pyrex/Steel - DYNA2D Set-Up 


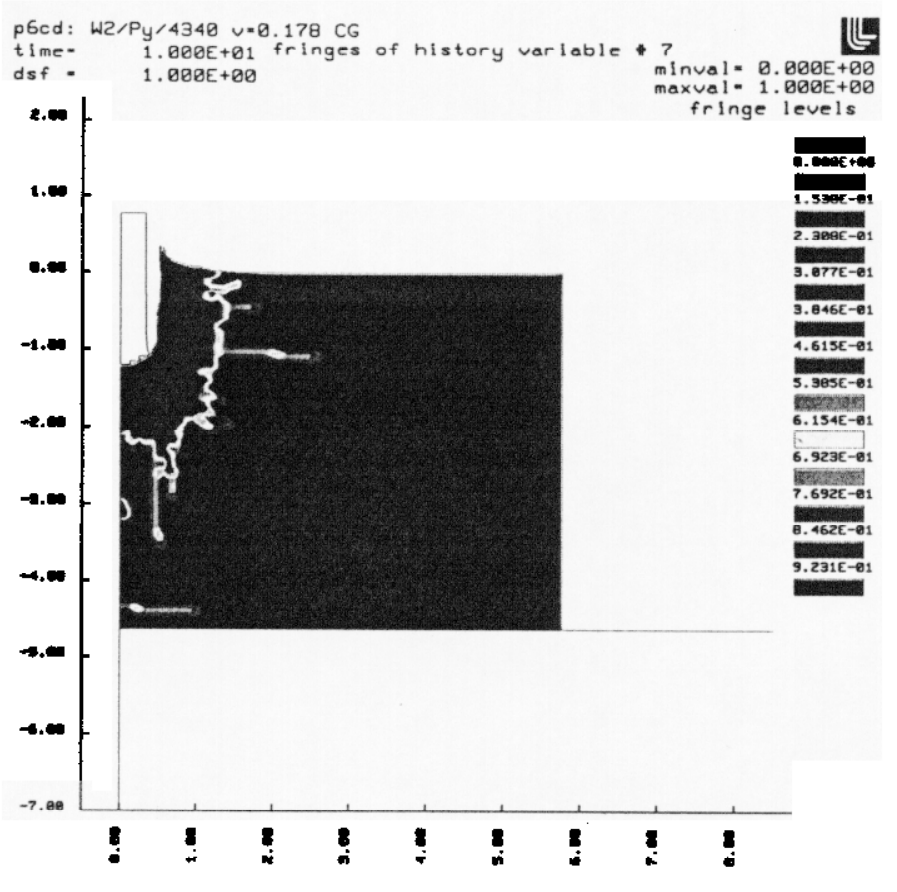

Figure 13: Tungsten/Pyrex/Steel - Modified Cagnoux-Glenn Model (Case 8): 10 microseconds After Impact: Fringe of Damage, 1 = Completely Failed

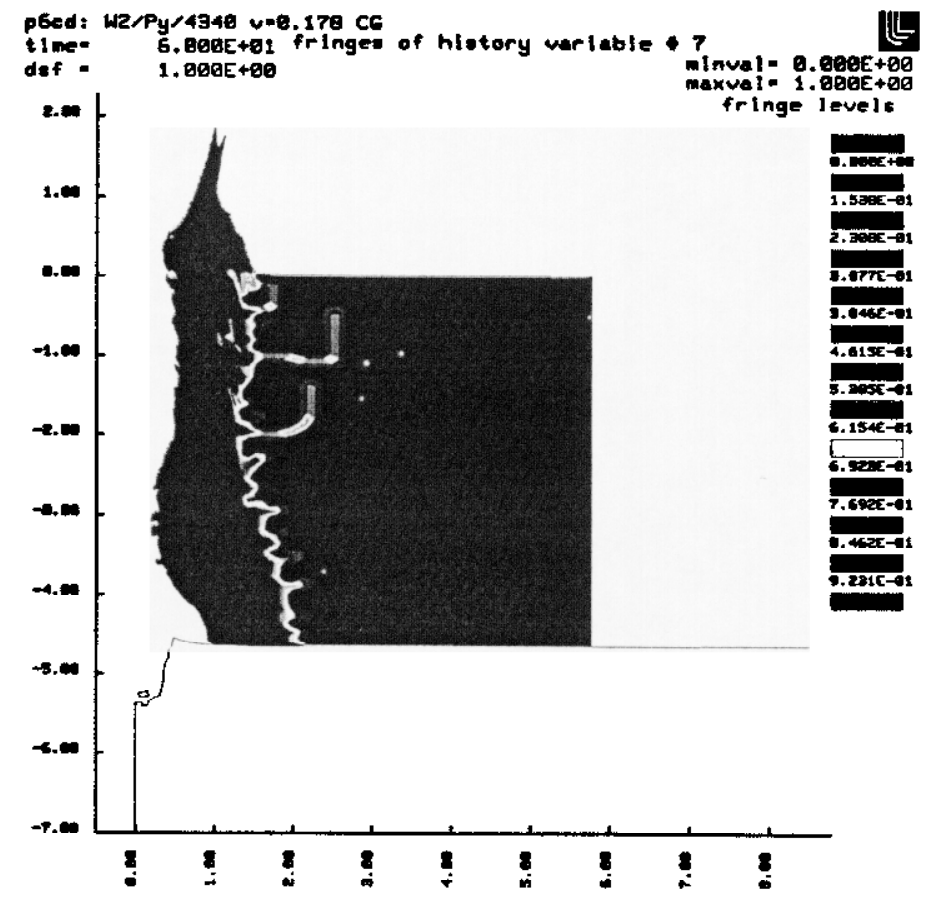

Figure 14: Tungsten/Pyrex/Steel - Modified Cagnoux-Glenn Model (Case 8): 60 microseconds After Impact: Fringe of Damage, $1=$ Completely Failed 


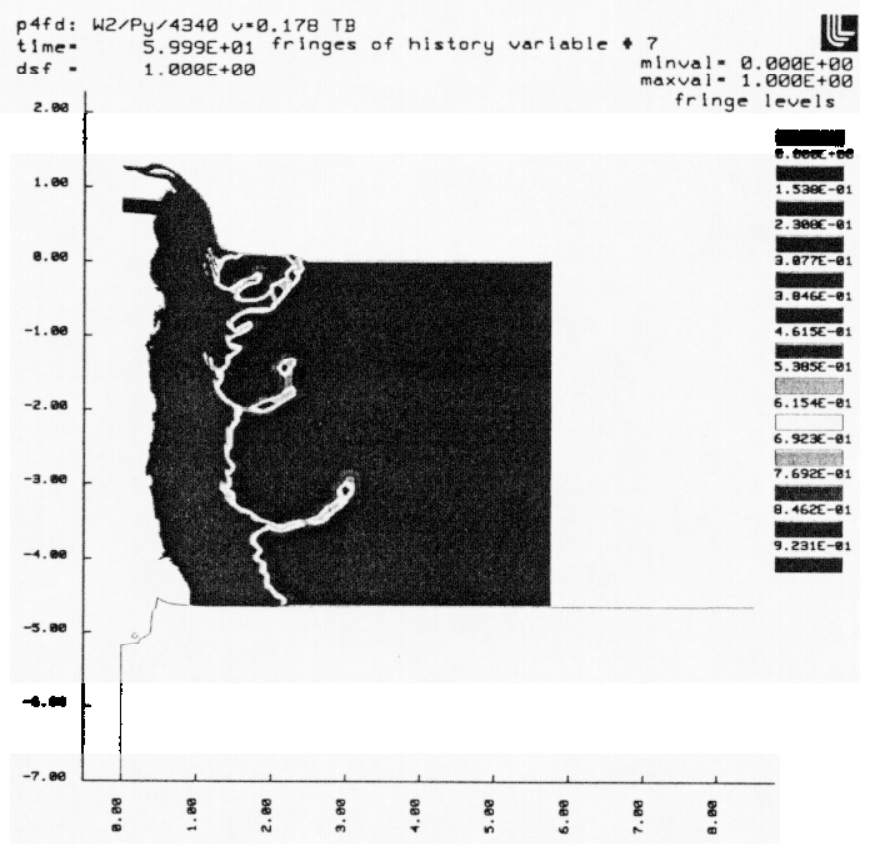

Figure 15: Tungsten/Pyrex/Steel - Modified Tuler-Butcher Model (Case 9): 60 microseconds After Impact: Fringe of Damage, 1 = Completely Failed

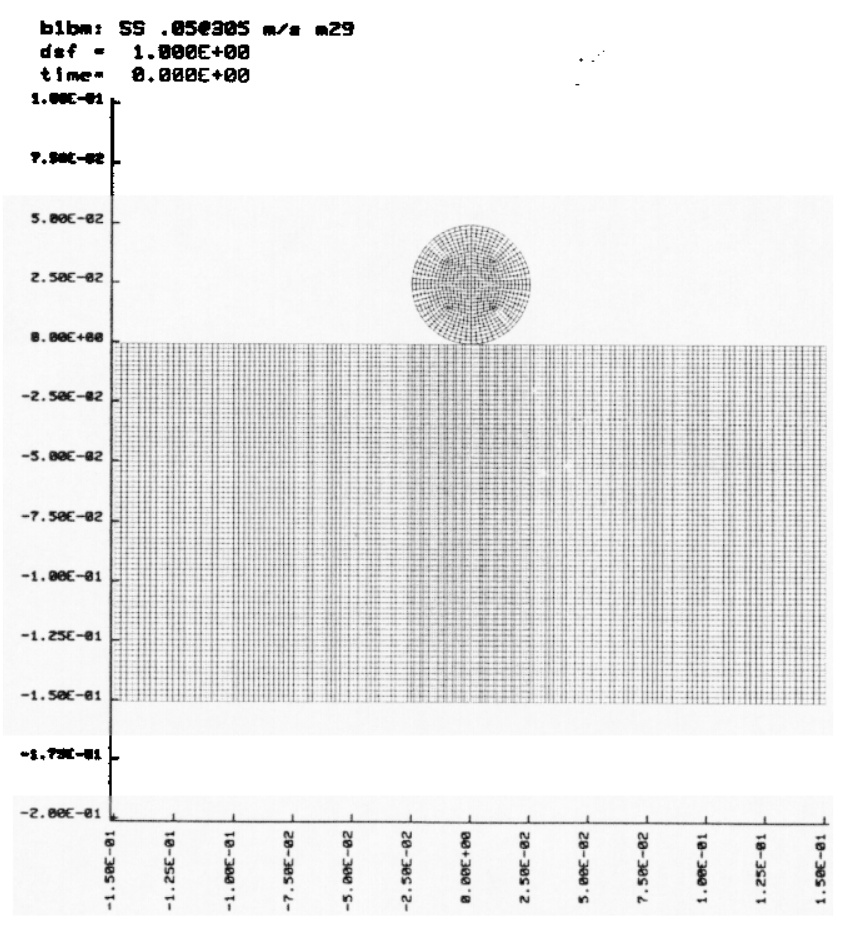

Figure 16: Steel Ball on Fused Silica - DYNA2D Set-Up 


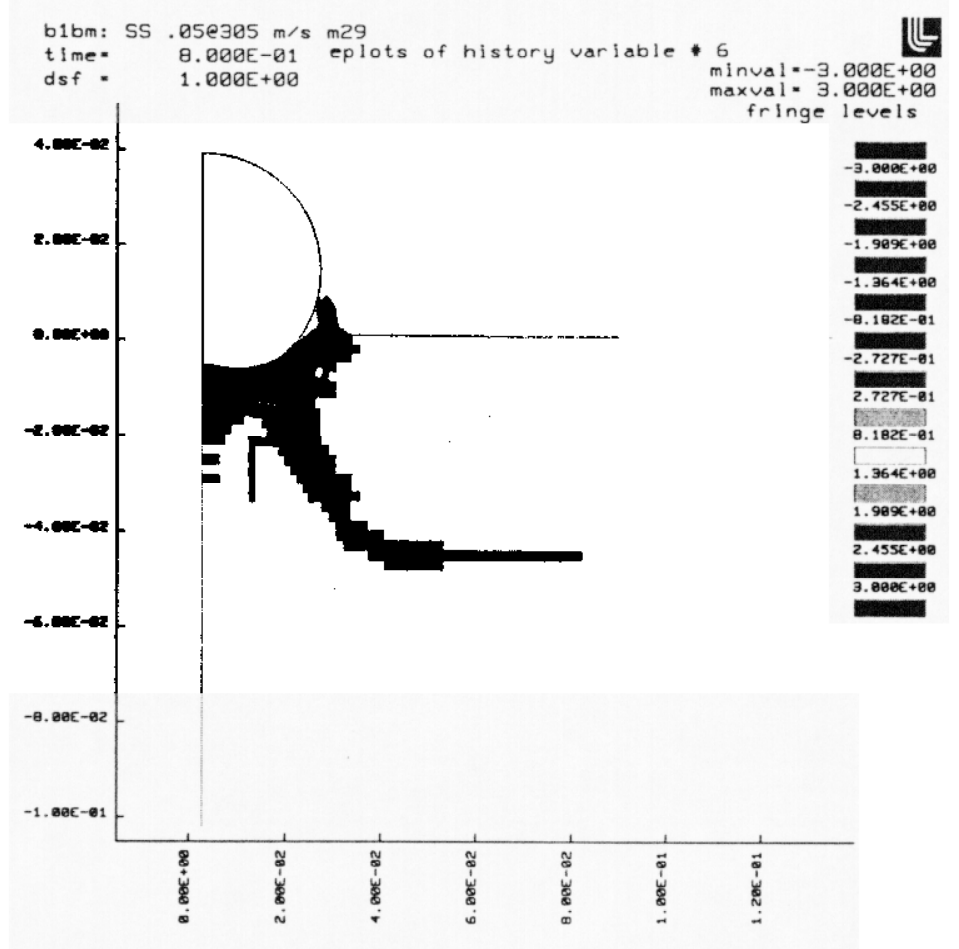

Figure 17: Steel Ball on Fused Silica - 3D-Crack Model (Case 10): 80 microseconds After Impact: Element fringe plot of number of cracks.

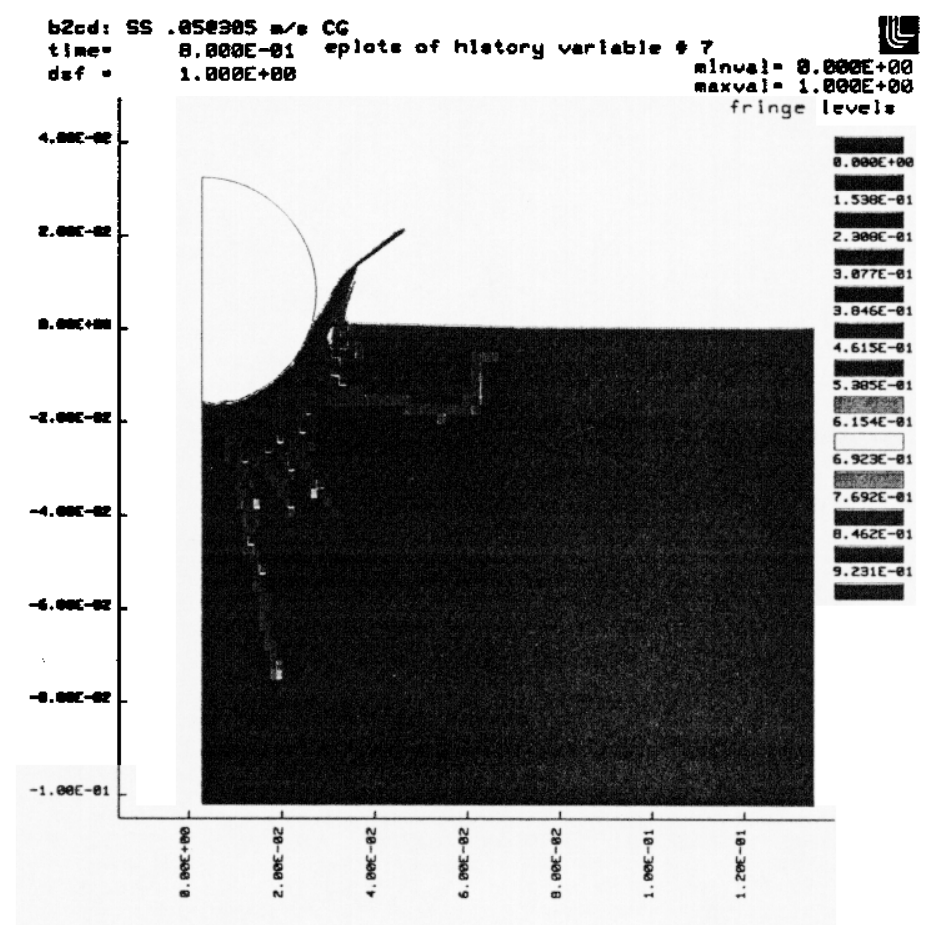

Figure 18: Steel Ball on Fused Silica - Modified Cagnoux-Glenn Model (Case 11): 80 microseconds After Impact: element fringe plot of damage, 1 = Completely Failed 


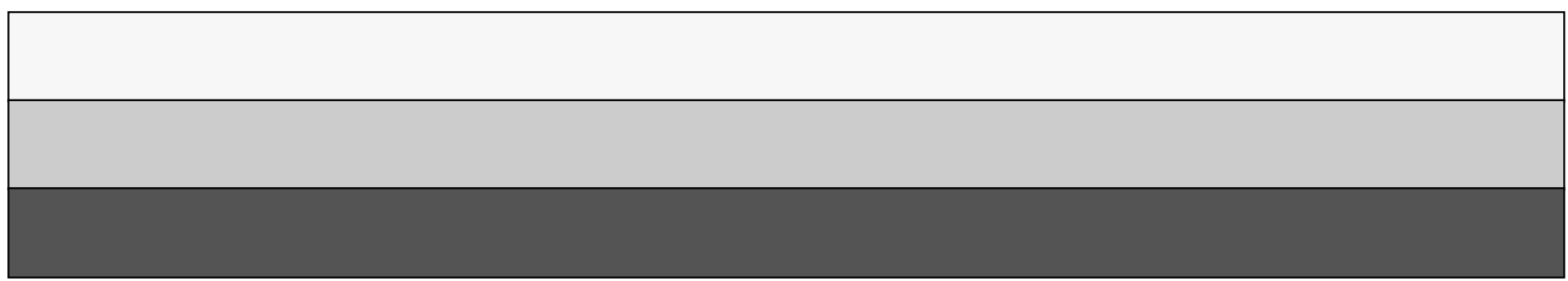

